\title{
Anterior Surface of the Lens
}

National Cancer Institute

\section{Source}

National Cancer Institute. Anterior Surface of the Lens. NCI Thesaurus. Code C32108.

The anterior surface of the lens of the eye. 